
$\begin{array}{lrr}* \text { Mestre } & \text { pela } & \text { PUC/PR. } \\ \text { Especialista } & \text { em } & \text { Direito }\end{array}$ Constitucional pela Universidade Anhanguera/UNIDERP.

Especialista em Direito do Trabalho pela AMATRA 12 em convênio com a UNIVALI. Advogada.

E-mail: carolinebelletti@yahoo. com.br

\footnotetext{
** Mestre e Doutor pela PUCSP; professor titular da PUCPR (Curitiba, PR-Brasil) onde leciona na graduação, especializações, mestrado e doutorado; professor da Escola da Magistratura do Paraná; membro do Instituto dos Advogados do Paraná; Advogado militante em Curitiba.

E-mail: ace@eradv.com.br
}

\section{Relações de Consumo e Serviços Públicos: A Figura do Estado Consumidor}

\author{
Consumer Relations and Public Services: the Figure \\ of THE State as a Consumer
}

\section{Caroline Belletti* Antônio Carlos Efing**}

Como citar: BELLETTI, Caroline; EFING, Antonio Carlos. Relações de consumo e serviços públicos: a figura do estado consumidor. Revista do Direito Público, Londrina, v. 14, n. 3, p. 168-183, dez. 2019. DOI: 10.5433/24157-108104-1.2019v14 n3p. 168. ISSN: 1980-511X

Resumo: O presente estudo busca apresentar o conceito de serviços públicos, de consumidor e de fornecedor a fim de discorrer acerca da possibilidade de aplicação do diploma consumerista na prestação dos serviços públicos e na figura do Estado como consumidor. Para isso, utilizou-se a técnica de pesquisa bibliográfica para instrumentalizar o presente artigo científico, através da base lógica indutiva para relatar os resultados do trabalho.

Palavras-chave: Relações de consumo. Serviços públicos. Estado consumidor.

Abstract: This study explores the concept of public services both in consumer and supplier aspects - in order to better discuss the possibility of applying the consumer law in the provision of public services and in the figure of the State as a consumer. For this purpose, this paper utilized literature review and the inductive logical model in order to discuss the results of this work.

Keywords: Consumer relations. Public services. State consumer. 


\section{INTRODUÇÃO}

O presente artigo tem como objeto de estudo a discussão doutrinária sobre a incidência ou não do Código de Defesa do Consumidor quando da prestação de serviços públicos por parte do Estado e a aplicação destas normas consumeristas quando o Estado atua como consumidor.

O interesse nessa pesquisa surgiu pela leitura de diversas obras de Direito Administrativo, Direito do Consumidor, jurisprudência de diversos tribunais brasileiros acerca do tema e, inclusive, pela leitura do artigo $3^{\circ}$ do Código de Defesa do Consumidor que traz o conceito de fornecedor.

Em que pese várias consequências jurídicas advirem da aplicação ou não do Código de Defesa do Consumidor na prestação dos serviços públicos, observa-se que este assunto ainda é controverso. Ao passo que o artigo $2^{\circ}$ e $3^{\circ}$ do CDC trazem, respectivamente, que "Consumidor é toda pessoa física ou jurídica que adquire ou utiliza produto ou serviço como destinatário final" e que "Fornecedor é toda pessoa física ou jurídica, pública ou privada" (BRASIL, 2014a), entendese que o Estado, então, poderia ser enquadrado nas duas categorias, aplicando-se contra e a seu favor as normas previstas neste Código. Por outro lado, o artigo 22 do mesmo Codex traz que:

Art. 22. Os órgãos públicos, por si ou suas empresas, concessionárias, permissionárias ou sob qualquer outra forma de empreendimento, são obrigados a fornecer serviços adequados, eficientes, seguros e, quanto aos essenciais, contínuos.

Parágrafo único. Nos casos de descumprimento, total ou parcial, das obrigações referidas neste artigo, serão as pessoas jurídicas compelidas a cumpri-las e a reparar os danos causados, na forma prevista neste código (BRASIL, 2014a, p. $\mathrm{x})$.

Ou seja, apenas os serviços públicos que atendam usuários determináveis (uti singuli) e que tenham incidência das taxas que trata o artigo 145, inciso II, da Constituição Federal é que poderiam ser objeto do CDC. Quanto aos demais serviços ("uti universi”), não haveria incidência das normas consumeristas (AGUILLAR, 2010).

Assim, a solução para o caso concreto geralmente é alcançada pelo suporte dado pelos doutrinadores e pelo entendimento dos tribunais, fontes que serão estudadas nesse artigo para análise do tema.

Para isso, a presente pesquisa parte da seguinte problemática: Há possibilidade de incidência das normas previstas no Código de Defesa do Consumidor na prestação de serviços públicos? Nesse contexto, existem hipóteses em que o próprio Estado poderia ser considerado como consumidor ou ele atua sempre como fornecedor?

O presente estudo utiliza como método na fase investigatória, a base lógica Indutiva, 
além das Técnicas do Referente ${ }^{2}$, da Categoria ${ }^{3}$, do Conceito Operacional ${ }^{4}$ e da Pesquisa Bibliográfica ${ }^{5}$.

\section{SERVIÇOS PÚBLICOS}

Os elementos constitutivos da figura do Estado são apontados pela doutrina em geral como três, sendo eles o povo, o governo e o território. Dentro dessa estrutura, o governo se legitima através do povo e este, por sua vez, necessita do poder de organização do governo para a convivência pacífica da sociedade (FERREIRA FILHO, 2011, p. 75).

Cada integrante do povo necessita de determinadas comodidades e utilidades que podem ser atendidas por meios e recursos que cada um dos membros da comunidade possui ou, algumas, só podem ser satisfeitas através de atividades a cargo da Administração Pública, surgindo assim a necessidade de prestação dos chamados serviços públicos pela Administração.

Diogenes Gasparini aponta que o termo serviço público comporta, pelo menos, três sentidos: o orgânico, o material e o formal (GASPARINI, 2012, p. 349).

No sentido orgânico, que também é chamado pelo doutrinador de subjetivo, o serviço público poderia ser conceituado como o conjunto de órgãos, agentes e recursos da Administração Pública que se destinam à satisfação das necessidades dos administrados (GASPARINI, 2012, p. 349).

Partindo-se do enfoque material, também chamado de objetivo, o serviço público teria como definição uma função, uma tarefa ou uma atividade da Administração Pública destinada a satisfazer necessidades de interesse geral dos administrados (GASPARINI, 2012, p. 349).

Por fim, para o sentido formal, serviço público seria a atividade desempenhada pelo Poder Público ou seus delegados, sob regras exorbitantes do Direito Comum, para satisfação dos interesses dos administrados. Seria, então, a submissão de certa atividade a um regime de Direito Público (GASPARINI, 2012, p. 349).

Ocorre que com o passar do tempo e o aumento da população mundial em geral, o Estado passou a carecer de instrumentos suficientes para a realização adequada da vasta gama de serviços públicos necessários ao bom atendimento da comunidade (DI PIETRO, 2015, p. 139).

Ao longo do tempo, o instituto do serviço público tem experimentado seguidas crises. Nos últimos anos, chegou a se proclamar sua morte. Analisando a questão, Marçal Justen Filho (2015, p. 742) destaca que a concepção de crise deve ser entendida como a necessidade de adequação do instituto às circunstâncias sociais e econômicas.

Assim, o Estado passou a delegar a execução de determinadas tarefas a particulares, por meio de contratos de concessão de serviços públicos e, posteriormente, por meio de pessoas jurídicas de direito privado instituídas para tal fim, como empresas públicas e sociedades de

2 “[...] explicitação prévia do(s) motivo(s), do(s) objetivo(s) e do produto desejado, delimitando o alcance temático e de abordagem para a atividade intelectual, especialmente para uma pesquisa." (PASOLD, 2008, p. 53).

3 “[...] palavra ou expressão estratégica à elaboração e/ou à expressão de uma idéia." (PASOLD, 2008, p. 25).

4 "…] uma definição para uma palavra ou expressão, com o desejo de que tal definição seja aceita para os efeitos das ideias que expomos [...]". (PASOLD, 2008, p. 37). 
economia mista, visando a execução de tais atividades sob regime jurídico predominantemente privado (DI PIETRO, 2015, p. 139).

Todavia, com o advento de ramo específico do Direito para a tutela e garantia dos direitos do consumidor, surge a problemática em relação à inclusão ou não dos serviços públicos dentro da esfera de proteção do diploma consumerista (Lei n. ${ }^{0}$ 8.078/90) e, nesse mesmo sentido, da possibilidade da figura do Estado ser vista como consumidora em determinadas relações jurídicas (BRASIL, 1990).

Antes de adentrar mais aprofundadamente na discussão específica acerca do tema, fazse necessário esclarecer os princípios que devem nortear a prestação dos serviços públicos e o conceito de consumidor, definições pertinentes para abordagem da problemática.

\subsection{Princípios Que Norteiam A Prestação Dos Serviços Públicos}

Sendo voltados aos membros da coletividade, os serviços públicos a cargo do Estado ou de seus delegados devem obedecer a certos padrões compatíveis com o prestador, os destinatários e o regime a que se sujeitam (CARVALHO FILHO, 2015, p. 342).

Segundo Carvalho Filho (2015, p. 342), cada tipo de serviço público deve seguir determinados aspectos particulares. Todavia, existem alguns vetores, que são de caráter genérico e, portanto, devem estar presentes na prestação de todas as modalidades de serviços públicos. Seriam, pois, esses aspectos genéricos os chamados princípios norteadores da prestação dos serviços públicos.

A doutrina em geral costuma apontar como princípios básicos determinadores dos serviços públicos a regularidade, a continuidade, a eficiência, a segurança, a atualidade, a generalidade, a cortesia e a modicidade (CARVALHO FILHO, 2015, p. 342).

Nesse mesmo sentido, a Lei $n^{\circ} 8.987 / 1995$ (BRASIL, 1995) que regulamenta o regime de concessão e permissão da prestação de serviços públicos previsto no artigo 175 da Constituição Federal caracteriza o serviço adequado nos seguintes termos: "Art. $6^{\circ}, \S 1^{\circ}$ Serviço adequado é o que satisfaz as condições de regularidade, continuidade, eficiência, segurança, atualidade, generalidade, cortesia na sua prestação e modicidade das tarifas." (BRASIL, 2014b).

Por sua vez, o artigo 22 do Código de Defesa do Consumidor ${ }^{6}$ também prevê que os órgãos públicos são obrigados a fornecer serviços que atendam a determinados quesitos.

\section{O CONCEITO DE CONSUMIDOR}

O consumo é parte indissociável do cotidiano do ser humano. Destaca João Batista de Almeida (2009, p. 1) ser verdadeira a afirmação de que todos nós somos consumidores. Independentemente da classe social e da faixa de renda, consumimos desde o nascimento e em

6 Art. 22 Os órgãos públicos, por si ou suas empresas concessionárias, permissionárias ou sob qualquer outra forma de empreendimento, são obrigados a fornecer serviços, adequados, eficientes, seguros e, quanto aos essenciais, contínuos (BRASIL, 2014a). 
todos os períodos de nossa existência por motivos variados, que vão desde a necessidade de sobrevivência até o consumo por simples desejo, o consumo pelo consumo.

Destaca a doutrinadora Cláudia Lima Marques que o vocábulo "consumidor" foi reconhecido pelo direito recentemente, mais especificamente nas décadas 60-70 do século XX, antes disso era tratado simplesmente como "contratante", "cliente" ou "comprador". (BENJAMIN; MARQUES; BESSA, 2012, p. 29).

Segundo Benjamin, Marques ou Bessa (2012, p. 29) o chamado direito do consumidor é um ramo novo do direito, uma disciplina transversal entre o direito privado e o direito público, que visa proteger um sujeito de direitos, o consumidor, em todas as suas relações jurídicas frente ao fornecedor, um profissional, empresário ou comerciante.

De forma objetiva e direta o Código de Defesa do Consumidor, em seu artigo $2^{\circ}$, conceitua consumidor como:

Art. $2^{\circ}$ Consumidor é toda pessoa física ou jurídica que adquire ou utiliza produto ou serviço como destinatário final.

Parágrafo único. Equipara-se a consumidor a coletividade de pessoas, ainda que indetermináveis, que haja intervindo nas relações de consumo (BRASIL, 2014a, p. $\mathrm{x})$.

Fazendo uma análise mais aprofundada acerca do conceito de consumidor, José Geraldo Brito Filomeno (2010, p. 18) traz três acepções diferentes para o termo levando em conta o aspecto econômico, o psicológico e o sociológico.

Sob o ponto de vista econômico, consumidor seria todo sujeito que atua como destinatário da produção de bens, mesmo que não seja adquirente da referida produção e seja ou não também produtor de outros bens (FILOMENO, 2010, p. 18).

Já pelo sentido psicológico do termo, consumidor é conceituado por Filomeno como o indivíduo sobre o qual se estudam as reações a fim de individualizar os critérios para a produção e as motivações internas que o levam ao consumo. Nesse norte, procura se preocupar com as circunstâncias subjetivas que levam determinado indivíduo ou grupo de indivíduos a ter preferência por determinado tipo de produto ou serviço, adentrando e analisando também a ciência do marketing e da publicidade, inclusive os devastadores efeitos dessa quando enganosa ou tendenciosa (FILOMENO, 2010, p. 18).

Por fim, o sentido sociológico conceituaria consumidor como qualquer indivíduo que frui ou se utiliza de bens e serviços, mas pertencente a uma determinada categoria ou classe social (FILOMENO, 2010, p. 18).

Ainda, há três teorias principais que definem quem pode ser considerado como consumidor, a finalista, a maximalista e o finalista aprofundado. A primeira, respectivamente, tem um visão mais restrita de quem pode ser enquadrado como consumidor, sendo somente o destinatário final fático e econômico, aqueles não-profissionais, não-especialistas, excluindo, até mesmo, em 
alguns casos, a pessoa jurídica. Já a maximalista, como o próprio nome já traz, tem uma maior abrangência e identifica como consumidor o destinatário fático do produto ou serviço, ainda que não o seja necessariamente seu destinatário econômico. De acordo com esta corrente, o Estado poderia ser considerado consumidor quando compra produtos para uso próprio em suas atividades administrativas. Por fim, a teoria do finalismo aprofundado, também chamada de mitigada, é aquela que entende o critério da vulnerabilidade como característica essencial do consumidor, sem ela, descaracteriza-se a figura do consumidor. Tal corrente é a adotada pelo ordenamento jurídico brasileiro (MIRAGEM, 2008, p. 86-92).

Aponta Rizzatto Nunes (2015, p. 65) que nas relações contratuais, no direito civil, pressupõe-se que aqueles que querem contratar sentam-se à mesa em igualdade de condições e transmitem o elemento volitivo de dentro para fora, transformando em dado objetivo num pedaço de papel. Todavia, destaca o doutrinador que isso não acontece nas relações de consumo, onde é evidente a hipossuficiência do consumidor e a desigualdade de condições.

Inclusive nesse sentido destaca Antônio Carlos Efing (2000, p. 22) que nas relações de consumo o consumidor deveria ser visto a partir da figura do "homem mínimo", e não médio, tendo em vista a sua hipossuficiência e vulnerabilidade.

O consenso internacional em relação à vulnerabilidade do consumidor no mercado de consumo representou fator importante para o surgimento da tutela no nível de cada país. $\mathrm{O}$ reconhecimento de que o consumidor estava desprotegido em termos educacionais, informativos, materiais e legislativos determinou maior atenção para o problema e o aparecimento de legislação protetiva em vários países (ALMEIDA, 2009, p. 4).

Então, a partir desse consenso e visando o bem-estar da sociedade e das relações humanas, como bem assevera Efing (2000, p. 22), passou a ser consagrada a proteção ao consumidor e a preocupação com os acidentes advindos do uso de produtos e serviços e, por consequência, com a qualidade destes produtos e serviços, bem como a sua proteção no mercado de consumo contra práticas abusivas e no campo da proteção contratual.

No texto constitucional brasileiro a defesa do consumidor está prevista como um dos princípios gerais da atividade econômica, no art. 170, inciso V. A Carta Magna ainda impõe ao Estado o dever de promover tal defesa, em seu art. $5^{\circ}$, inciso XXXII. Visando dar efetividade às referidas disposições constitucionais, é editada em 1990 a Lei no 8.078/90 que instituiu o Código de Defesa do Consumidor.

Benjamin, Marques e Bessa (2012, p. 58) define o Código de Defesa do Consumidor como uma lei de função social, que traz normas de direito privado, mas de ordem pública, e normas de direito público. É também lei de ordem pública econômica e lei de interesse social. Constitui, assim, um microssistema, como costuma chamar a maioria da doutrina, que busca dar efetividade à proteção do consumidor (parte hipossuficiente da relação jurídica) prevista na Constituição Federal de 1988.

Para interpretar adequadamente o Código de Defesa do Consumidor é preciso ter em mente que as relações jurídicas estabelecidas são atreladas ao sistema de produção massificado, o que faz 
com que se deva privilegiar o coletivo e o difuso, bem como que se leve em consideração que as relações jurídicas são fixadas de antemão e unilateralmente por uma das partes - o fornecedor -, vinculando de uma só vez milhares de consumidores, conforme alerta Nunes (2015, p. 65).

Antes de aplicar a lei consumerista ao caso concreto e de efetivar a proteção que o diploma outorga ao consumidor, é de suma importância a certeza de que a relação jurídica é de consumo. Em se tratando de contratos entre particulares a questão não envolve maiores discussões. Todavia, a questão pode não ser tão simples nos contratos entre particulares e o ente estatal. Nesse contexto, busca-se a seguir investigar a possibilidade de aplicação desse microssistema de proteção do consumidor na prestação de serviços públicos.

\section{A POSSIBILIDADE DE APLICAÇÃO DO CÓDIGO DE DEFESA DO CONSUMIDOR AOS SERVIÇOS PÚBLICOS}

Para a eficaz proteção do consumidor é essencial que o intérprete, o juiz ou o aplicador da lei saiba com exatidão se a situação que lhe é apresentada consiste em relação de consumo e se cabível a incidência do Código de Defesa do Consumidor no caso concreto. (BENJAMIN; MARQUES; BESSA, 2012, p. 85).

Nesse sentido, coloca Benjamin, Marques e Bessa (2012, p. 85) que o grande desafio do intérprete e aplicador do $\mathrm{CDC}$, como código que regula uma relação jurídica entre privados, é saber diferenciar e saber identificar quem é comerciante, quem é civil, quem é consumidor, quem é fornecedor, quem faz parte da cadeia de produção e de distribuição, quem retira o bem do mercado como destinatário final e quem é equiparado a este, seja porque é uma coletividade que intervém na relação, porque é vítima de um acidente de consumo ou porque foi quem criou o risco no mercado.

Assim, Benjamin, Marques e Bessa (2012, p. 85) conclui que no caso do CDC é este exercício, de definir quem é o sujeito ou quem são os sujeitos da relação contratual e extracontratual, que vai definir o campo de aplicação desta lei, isto é, a que relações ela se aplica.

Visando nortear o campo de aplicação do diploma legal, o art. $3^{\circ}$ do Código de Defesa do Consumidor estabelece que fornecedor é:

Art. $3^{\circ}$ Fornecedor é toda pessoa física ou jurídica, pública ou privada, nacional ou estrangeira, bem como os entes despersonalizados, que desenvolvem atividades de produção, montagem, criação, construção, transformação, importação, exportação, distribuição ou comercialização de produtos ou prestação de serviços (BRASIL, 2014a, p. x).

No que diz respeito aos serviços públicos, segundo Gasparini (2012, p. 367), sempre que a Administração Pública, em qualquer de suas manifestações (federal, estadual, distrital e municipal), figurar como fornecedora, submete-se integralmente às disposições do diploma consumerista.

Também aponta Rizzatto Nunes (2015, p. 198) que estão compreendidos na ampla 
regulação da lei consumerista os serviços públicos, sem ressalvas. Afirma ainda que se se levar em consideração que as duas exceções para a não abrangência do CDC no que diz respeito aos serviços públicos (sem efetiva remuneração e custo; os de caráter trabalhista), ter-se-á de concluir que praticamente todos os serviços públicos estão protegidos pela Lei nº 8.078/90.

Segundo Nunes (2015, p. 198) não é porque algum tipo de serviço público não esteja sendo pago diretamente - ou nem sequer esteja sendo cobrado - que não está abrangido pelas regras do CDC. Alega ainda que nenhum serviço pode ser considerado efetivamente gratuito, já que todos são criados, mantidos e oferecidos a partir da receita advinda da arrecadação dos tributos.

O mesmo entendimento é compartilhado por Almeida (2009, p. 324) que afirma que em um país como o Brasil, em que 62,3 milhões de habitantes encontram-se abaixo da linha de pobreza, apresenta-se mais evidente a importância do Estado no papel de promotor do bem-estar da população e de responsável pela melhoria da qualidade de vida.

Fato é que o Estado, na sua função de proporcionar o bem-estar da população, é um grande prestador de serviços, alguns deles básicos ou essenciais, como saúde, educação, transporte, habitação, segurança pública, saneamento básico, água, esgoto e comunicação (ALMEIDA, 2009, p. 324).

No mesmo norte Renato Afonso Gonçalves (2014. p. 75) afirma que o Estado caracterizase por ser um dos principais fornecedores no mercado de consumo. Assim, os órgãos públicos, por si ou suas empresas, concessionárias, permissionárias ou sob qualquer oura forma de empreendimento, são obrigados a fornecer serviços adequados, eficientes, seguros e, quanto aos essenciais, contínuos, podendo se valer o usuário dos referidos serviços das normas previstas no diploma consumerista quando não forem prestados da forma como deveriam, isto é, quando não preencherem os requisitos mínimos previstos em lei.

No entanto, alguns doutrinadores como Marques (2002, p. 485) e Filomeno (2001, p. 44) excluem da incidência do Código de Defesa do Consumidor os serviços custeados pelos impostos, em relação aos quais não há pagamento direto e imediato por parte do usuário. Assim, preveem a incidência do CDC aos serviços públicos, mas com algumas ressalvas.

Há de se destacar ainda que existem entendimentos minoritários, como o de Adalberto Pasqualoto (1992, p. 130-148) que entende que a disciplina dos serviços públicos em relação ao consumidor exaure-se na descrição do art. 22 do Código de Defesa do Consumidor, sendo que os demais dispositivos da norma devem devem ser interpretados como diretriz administrativa, donde se poderia concluir que não possuem efeito vinculante, mas apenas atuam como norte para a interpretação das normas específicas, com incidência direta sobre a prestação de tais serviços. Todavia, esse entendimento não parece predominar na doutrina, tampouco na jurisprudência dos tribunais.

Sob o ponto de vista dos julgadores, que aplicam o direito ao caso concreto, destaca Tani Maria Wurster (2015), juíza federal do Tribunal Regional Federal da $4^{\text {a }}$ Região, que o próprio Código de Defesa do Consumidor, pretendendo dar concretude às normas constitucionais, determinou expressamente a incidência do sistema de proteção especial previsto na Lei $\mathrm{n}^{\circ}$ 8.078/90 
à prestação dos serviços públicos. Segundo a juíza, tal conclusão é possível não só pela análise das normas já referenciadas, como dos próprios conceitos de consumidor, fornecedor, produto e serviço fixados no código consumerista.

Nessa mesma linha, oportuno citar a decisão proferida nos autos 000720819.2014.8.16.0165/07 , em 06/07/2015, pela $1^{\text {a }}$ Turma Recursal do Tribunal de Justiça do Estado do Paraná, onde a Recorrente, empresa que possui a concessão de rodovia pedagiada, pleiteava eximir-se da condenação ao pagamento de indenização referente aos danos materiais ocorridos no veículo do usuário, advindos de acidente de trânsito.

Segundo a $1^{\text {a }}$ Turma Recursal, o caso em questão trata-se de típica relação de consumo, nos termos dos artigos $2^{\circ}$ e $3^{\circ}$ do Código de Defesa do Consumidor, sendo conferida ao usuário da rodovia a possibilidade de invocar o diploma consumerista para facilitação dos seus direitos. Além disso, a turma destacou a obrigação das concessionárias de serviço público em fornecer serviços adequados, eficientes e seguros aos consumidores.

Também se destaca a decisão proferida nos autos $70053980587^{8}$, em $06 / 08 / 2014$, pela $1^{\text {a }}$ Câmara Cível do Tribunal de Justiça do Estado do Rio Grande do Sul, onde a Recorrente, companhia fornecedora de água, buscava reformar a sentença de primeiro grau que não reconheceu devida a cobrança de multa por violação do hidrômetro, alegando ser válida a cobrança apenas quando a

7 Acórdão: ACIDENTE EM RODOVIA PEDAGIADA. TRATA-SE DE ACIDENTE DE TRÂNSITO EM RODOVIA PEDAGIADA EM QUE O VEÍCULO DO RECLAMANTE COLIDIU COM ANIMAL NA PISTA. ALEGA QUE A COLISÃO RESULTOU EM AVARIAS EM SEU VEÍCULO SOBREVEIO SENTENÇA DE PROCEDENCIA QUE CONDENOU AO PAGAMENTO DE INDENIZAÇÃO POR DANOS MATERIAIS NO IMPORTE DE R\$ 5.715,93. INSURGÊNCIA RECURSAL DA RECLAMADA. PUGNA PELO AFASTAMENTO DA RESPONSABILIDADE OBJETIVA, ALEGA EXCLUDENTE DE RESPONSABILIDADE CONSISTENTE NA FORCCA MAIOR E CULPA DE TERCEIRO E AFASTAMENTO DA CONDENAÇÃO. A MATÉRIA TRATADA NOS AUTOS REFERE-SE A UMA TÍPICA RELAÇÃO DE CONSUMO, NOS TERMOS DOS ARTIGOS $2^{\circ}$ E $3^{\circ}$ DO CÓDIGO DE DEFESA DO CONSUMIDOR, SENDO CONFERIDO AO CONSUMIDOR A FACILITAÇÃO DA DEFESA DOS SEUS DIREITOS, NOS TERMOS DO ART. $6^{\circ}$, INCISO VIII, DO CDC. AINDA, A RESPONSABILIDADE OBJETIVA DA RECORRENTE É PAUTADA NOS TERMOS DO ARTIGO $37, \S 6^{\circ}$ DA CONSTITUIÇÃO DA REPÚBLICA E ARTIGO 14 DO CÓDIGO DE DEFESA DO CONSUMIDOR. ALEM DISSO, O ART. 22 DO CDC ESTABELECE QUE AS CONCESSIONÁRIAS DE SERVICCO PÚBLICO SÃO OBRIGADAS A FORNECER SERVIÇOS ADEQUADOS, EFICIENTES E SEGUROS AOS CONSUMIDORES. INTELIGÊNCIA DO ENUNCIADO 8.4 DAS TRS/PR, NAS RELAÇÕES DE CONSUMO, A RESPONSABILIDADE DOS CONCESSIONÁRIOS DE SERVICO PÚBLICO É OBJETIVA, MESMO QUANDO FUNDADA EM ATO OMISSIVO. PORTANTO, É OBRIGAÇÃO DA EMPRESA RECORRENTE DESEMPENHAR DILIGENCIA SUFICIENTE E CAPAZ DE EVITAR QUE ANIMAIS ADENTREM NA PISTA SOB SUA ADMINISTRAÇÃO. DEVER DE INDENIZAR CONSUBSTANCIADO PELO ENUNCIADO 5.1 DAS TRS/PR: A RESPONSABILIDADE DAS CONCESSIONÁRIAS DE PEDÁGIO É OBJETIVA, (TJPR - $1^{\mathrm{a}}$ Turma Recursal - 0007208-19.2014.8.16.0165/0 - Telêmaco Borba - Rel.: Fernando Swain Ganem - - J. 06.07.2015) (TJPR - RI: 000720819201481601650 PR 0007208-19.2014.8.16.0165/0 (Acórdão), Relator: Fernando Swain Ganem, Data de Julgamento: 06/07/2015, $1^{\text {a }}$ Turma Recursal, Data de Publicação: 09/07/2015). (PARANÁ, 2015).

8 Acórdão: APELAÇÃO CÍVEL - CORSAN - FORNECIMENTO DE ÁGUA - PROBLEMA NO HIDRÔMETRO - APLICAÇÃO DE MULTA - ÔNUS DA PROVA - QUESTÃO DE FUNDO. 1. Ônus da prova. Na relação de consumo, vigora como regra a responsabilidade objetiva do fornecedor, tanto na relação de consumo comum quanto especial envolvendo os serviços públicos (CDC, art. 12; CF, art. 37, $\S 6^{\circ}$ ). Só vigora a subjetiva no caso de fornecedor profissional liberal (CDC, art. 14, $\S 4^{\circ}$ ). Neste caso, o juiz pode inverter o ônus da prova (inversão ope judici), desde que demonstrada a situação de hipossuficiência face ao fornecedor e a verossimilhança da alegação (CDC, art. $6^{\circ}$, VIII). Na responsabilidade objetiva, o ônus da prova se acha naturalmente invertido para o consumidor (inversão ope legis). 2. Questão de fundo. Cobrança de multa por violação do hidrômetro. Só é válida a cobrança de multa por violação de hidrômetro quando a retirada ocorre na presença do consumidor, com lavratura de Termo de Ocorrência de Inspeção ou Auto de Constatação, colhendo-se sua assinatura, ou certificando-se em caso de negativa. Não é válida a imposição de multa quando o agente não documenta adequadamente a ocorrência. Precedentes. 3. Dispositivo. Apelação desprovida. (Apelação Cível No 70053980587 , Primeira Câmara Cível, Tribunal de Justiça do RS, Relator: Irineu Mariani, Julgado em 06/08/2014) (TJ-RS - AC: 70053980587 RS , Relator: Irineu Mariani, Data de Julgamento: 06/08/2014, Primeira Câmara Cível, Data de Publicação: Diário da Justiça do dia 18/08/2014). (RIO GRANDE DE SUL, 2014). 
retirada do aparelho ocorre na presença do consumidor, com lavratura de termo de ocorrência de inspeção ou auto de constatação. No caso em questão, também reconheceu a $1^{\text {a }}$ Câmara Cível a incidência do CDC naquele caso concreto.

Percebe-se, pois, que vasto é o arcabouço doutrinário e jurisprudencial, no qual o Estado é destacado como um fornecedor, estando obrigado à prestação de serviços que devem atender padrões peculiares previstos em lei. Para resguardar seus direitos, é predominante o entendimento de que o usuário dos serviços públicos pode se socorrer do Código de Defesa do Consumidor quando entender que a prestação do serviço público não foi regularmente desempenhada.

Agora, cumpre analisar se existe possibilidade do Estado figurar na relação jurídica assumindo status de consumidor e quais as consequências jurídicas advindas.

\section{A FIGURA DO ESTADO CONSUMIDOR}

Aponta Flávio Amaral Garcia (2006, p. 50) que para uma parte dos doutrinadores, o ente estatal não poderia ser inserido no conceito de consumidor devido a duas razões mais especificamente: a primeira seria o fato de que, para que a pessoa possa ser considerada como consumidora, deve estar em situação de vulnerabilidade diante do fornecedor, ou seja, deve haver um desequilíbrio contratual. E, sendo assim, o Estado não poderia ser considerado vulnerável uma vez que detém de regime jurídico próprio para suas contratações, o qual busca tutelar o interesse da administração.

O segundo motivo estaria relacionado ao fato de que, diante do regime jurídico peculiar, o Estado tem a possibilidade de definir o tipo de prestação a ser adquirida e executada pelo particular, podendo previamente estipular as condições contratuais e descrever minuciosamente o objeto.

Tal posicionamento parece ser o mesmo do Superior Tribunal quando se analisa o AREsp 1041728, recurso pelo qual o policial militar buscava por indenização por parte da fabricante de armamentos, alegando que a arma de fogo que utilizava nas suas funções de policial havia sido disparada acidentalmente pelo mau funcionamento ou defeito de fabricação da pistola. O Relator do caso, Ministro Moura Ribeiro, assim decidiu:

O acórdão recorrido decidiu em conformidade com a jurisprudência desta Corte Superior, que, apesar de adotar a Teoria Finalista Mitigada, Abrandada ou Aprofundada como critério de aplicação da legislação consumerista, se orienta no sentido de que o ente estatal ocupa posição de supremacia em virtude do interesse público, sendo despido das características de vulnerabilidade técnica, científica, fática ou econômica perante o fornecedor que poderiam enquadrá-lo como consumidor, conforme o seguinte precedente (BRASIL, 2017).

Todavia, referido entendimento parece não ser o mais justo diante da complexidade de questões contratuais que podem deixar o Estado totalmente desprotegido na relação jurídica concreta. 
Em relação ao tema José Geraldo Brito Filomeno (2010, p. 36), também já questionou a hipótese e destacou a seguinte situação que lhe ocorreu quando funcionava como procurador-geral de justiça do Estado de São Paulo (2000-2002):

De certa feita, na qualidade de Coordenador das Promotorias de Justiça do Consumidor, constatamos, ao pedirmos frascos de corretor líquido ao almoxarifado, que muitos sequer tinham o produto, e outros tinham uma pequena quantidade. Imediatamente, contatamos o diretor-administrativo do Ministério Público, que procurou fazer valer nossos direitos de consumidora, enquanto instituição pública. E a pergunta que fica no ar é a seguinte: já que o art. $2^{\circ}$ do Código de Defesa do Consumidor fala em pessoa jurídica, não poderia o Ministério público ou outro organismo público ser considerado consumidor de produtos e serviços? (FILOMENO, 2010, p. 36).

Leon Frejda Szklarowsky (1999), subprocurador-geral aposentado da Fazenda Nacional, manifestando-se acerca do tema ("O código de proteção e defesa do consumidor e os contratos administrativos"), onde destaca que, sem dúvida, o Código de Defesa do Consumidor também é aplicado, ainda na hipótese de contrato administrativo, quando a contratante é a administração, sendo ela consumidora ou usuária porque adquire ou utiliza produto ou serviço como destinatária final.

Segundo Szklarowsky (1999), a lei não faz qualquer distinção entre as pessoas jurídicas que adquirem bens ou usufruem serviços. Sendo assim, não há por que negar a proteção dada pelo $\mathrm{CDC}$ ao Estado quando figura como consumidor, já que a estrutura estatal, seja atuando como consumidor ou usuária, nada mais é do que a própria sociedade representada ou organizada.

Assim, destaca que não se pode recusar à Administração Pública, quando for usuária ou consumidora, como destinatária final, a proteção legal do CDC, como a reparação de danos patrimoniais ou por defeitos relativos à prestação de serviços públicos (SZKLAROWSKY, 1999).

Ademais, não se pode mencionar que a Administração, apenas por gozar das benesses da lei especial a que se submetem os contratos administrativos, não necessita do agasalho do diploma consumerista. Isso porque, existem diversas outras situações que a lei específica dos contratos administrativos deixa de prever e então, evidente que a Administração não deve ficar ao desamparo, citando em sua obra o seguinte exemplo:

Tome-se, por exemplo, a prestação dos serviços de telefonia, fornecimento de gás, água e luz. Apregoar que a entendida privada ou pública, por ser parte da Administração, está afastada do manto protetor da Lei n. 8.078/90 é simplesmente absurdo e não se compatibiliza com o art. $2^{\circ}$ do Código. Servindose a Administração, como qualquer particular, dos serviços prestados por concessionárias do serviço público, não tem cabimento sua exclusão da proteção legal, o que feriria, brutalmente, a Constituição, que agasalha todo consumidor, sem exclusão de quem quer que seja. Aliás, o art. 54 expressamente indica com precisão matemática que os contratos administrativos rege-se pelas suas cláusulas e pelos preceitos 
de direito público e de direito privado e, ainda, pela teoria geral dos contratos, num harmônica constelação (SZKLAROWSKY, 1999).

Nesse sentido também afirma Garcia (2006, p. 55) que não seria razoável criar-se a expectativa de que um órgão ou entidade pública, por mais bem aparelhado que seja, disponha de servidores e técnicos que conheçam profundamente todos os objetos a serem adquiridos.

Outro forte argumento utilizado por Garcia (2006, p. 55) é o de que, em que pese a Administração Pública ter a possibilidade de definir o objeto da licitação, ela não deixa de adquirir senão os bens, serviços e obras que estão disponíveis no mercado e que são também adquiridos por todos os demais consumidores comuns. Assim, essa possibilidade de o ente público requisitar o objeto não faz com que se adquiram bens e serviços diferentes do setor privado e nem torna o Estado imune dos riscos que acometem os demais consumidores.

Rizzatto Nunes (2015, p. 182) ao apresentar em sua obra o conceito difuso de consumidor, menciona que desde já e desde sempre todas as pessoas são consumidoras por estarem potencialmente expostas a toda e qualquer prática comercial. Sendo assim, não há que se falar na exclusão do ente estatal do conceito de consumidor e, consequentemente, pode o Estado valer-se da proteção prevista no diploma consumerista quando lesionado em suas contratações.

Por fim, há quem diga também que a vulnerabilidade pode se apresentar para a administração pública nas relações de consume desde que sua área de atuação tenha relação com a área consumerista. Assim, quando não é comum àquele determinado órgão público litigar na área do direito do consumidor, seria então considerado vulnerável juridicamente (SILVA, 2014).

$\mathrm{O}$ que se pode extrair dos posicionamentos é que o Estado, ao adquirir produtos e serviços, acaba atuando como um consumidor ou usuário como outro qualquer ao passo que os produtos e serviços que adquire e utiliza não são diferentes daqueles utilizados pelo restante dos consumidores.

Por outro lado, em que pese a Administração Pública gozar de tutela específica que é a Lei de Licitações e Contratos Administrativos, o referido diploma não exaure a vasta gama de relações jurídicas e consequências as quais está sujeita a Administração visto que muitas hipóteses não estão previstas na Lei $n^{\circ}$ 8.666/93.

Assim, considerando que em determinadas hipóteses o Estado atua como um usuário/ consumidor como outro qualquer e que, por outro lado, a lei que rege as licitações e contratos administrativos não é capaz de abranger e tutelar a administração em todos os riscos aos quais está sujeita, sem dúvida que deve ser aceitável a invocação da tutela prevista no Código de Defesa do Consumidor para garantia de seus direitos e como forma de prevenção de abusos.

\section{CONSIDERAÇÕES FINAIS}

Para o desempenho das atividades do cotidiano, os membros da sociedade fazem uso de diversos serviços a fim de suprir suas necessidades básicas. Alguns desses serviços são fornecidos 
pelos particulares, e outros são prestados pelo próprio ente estatal.

No âmbito da sociedade brasileira, o Estado é sem dúvida um grande prestador de serviços, muitos deles de caráter básico ou essencial, como saúde, educação, transporte, habitação, segurança pública, saneamento básico, água, esgoto e comunicação.

Por sua vez, aquele que utiliza os serviços públicos como destinatário final também é considerado um consumidor como outro qualquer, a teor do disposto no art. $2^{\circ}$ do Código de Defesa do Consumidor que traz o conceito de consumidor.

Assim, nessa relação jurídica que envolve o Estado como fornecedor de serviços e o administrado como usuário, observou-se pela análise doutrinária e jurisprudencial, a possibilidade de incidência do diploma consumerista para a tutela dos interesses dos administrados/usuários.

Ocorre que, com o passar do tempo, houve aumento considerável da população, fazendo com que o número excessivo de usuários impedisse uma prestação eficaz pelas mãos do Estado da vasta gama de serviços públicos necessários à sociedade.

Visando solucionar a chamada crise no serviço público, o ente estatal passou a se valer de diversos institutos como o da desestatização, o da privatização, o do consócio público e de outras formas de execução indireta de serviços públicos.

Ao passo que o Estado delega para terceiros a prestação dos serviços públicos, passa a confiar e a ficar à mercê de produtos e serviços que não são fornecidos por ele próprio, ou seja, o Estado também passa a atuar como consumidor/usuário desses serviços prestados por terceiros.

Nesse contexto, o presente artigo buscou investigar a possibilidade de o ente estatal figurar como consumidor em determinadas relações jurídicas e a aplicação do Código de Defesa do Consumidor para tutela dos direitos da Administração Pública nas relações dessa espécie.

Chegou-se à conclusão de que não se pode excluir a Administração do conceito de consumidor apenas pelo fato de existir lei especial disciplinando os contratos administrativos. Até porque, como visto, existem diversas outras situações que a lei específica dos contratos administrativos deixa de prever e então, evidente que Administração fica totalmente desprotegida se é impedida de se valer do diploma consumerista.

Viu-se, a partir da jurisprudência e doutrina analisada, que o conceito de consumidor deve abranger todas as pessoas que estão potencialmente expostas a toda e qualquer prática comercial. Sendo assim, o ente estatal não deve ser excluído do conceito de consumidor e também tem a possibilidade de invocar a proteção prevista no diploma consumerista quando lesionado em suas contratações.

\section{REFERÊNCIAS}

AGUILLAR, Fernando. Se individualizado, serviço poderá ser cobrado. Revista Consultor Jurídico, São Paulo, 17 jul. 2010. Disponível em: https://www.conjur.com.br/2010-jul-17/servicopublico-individualizado-incidir-taxa. Acesso em: 18 fev. 2019. 
ALMEIDA, João Batista de. A proteção jurídica do consumidor. 7. ed. São Paulo: Saraiva, 2009.

BENJAMIN, Antonio Herman de Vasconcellos e; MARQUES, Claudia Lima; BESSA, Leonardo Roscoe. Manual de direito do consumidor. 4. ed. São Paulo: Revista dos Tribunais, 2012.

BRASIL. Código de defesa do consumidor. In: VADEMECUM compacto. 12. ed. São Paulo: Saraiva, 2014a.

BRASIL. Constituição da República Federativa do Brasil. In: VADEMECUM compacto. 12. ed. São Paulo: Saraiva, 2014b.

BRASIL. Lei $\mathbf{n}^{\mathbf{0}} \mathbf{8 . 9 8 7}$, de 13 de fevereiro de 1995. Dispõe sobre o regime de concessão e permissão da prestação de serviços públicos previsto no art. 175 da Constituição Federal, e dá outras providências. Brasília: Presidência da República, 1995. Disponível em: http://www.planalto. gov.br/ccivil_03/leis/L8987cons.htm. Acesso em: 21 jul. 2015.

BRASIL. Superior Tribunal de Justiça. Agravo em Recurso Especial: AREsp 1041728 DF 2017/0006604-0. Relator Min. Moura Ribeiro. Ação de indenização, disparo acidntal de arma de fogo efetuado por policial com equipamento da corporação. Publicação DJ 22 mar. 2017. Disponível em: https://stj.jusbrasil.com.br/jurisprudencia/442112759/agravo-em-recurso-especial-aresp1041728-df-2017-0006604-0. Acesso em: 18 fev. 2019.

CARVAlHO FILHO, José dos Santos. Manual de direito administrativo. 28. ed. São Paulo: Atlas, 2015.

DI PIETRO, Maria Sylvia Zanella. Direito administrativo. 28. ed. São Paulo: Atlas, 2015.

EFING, Antônio Carlos. Contratos e procedimento bancários à luz do código de defesa do consumidor. São Paulo: Revista dos Tribunais, 2000.

FERREIRA FILHO, Manoel Gonçalves. Curso de direito constitucional. 37. ed. São Paulo: Saraiva, 2011.

FILOMENO, José Geraldo Brito. Dos direitos básicos do consumidor. In: GRINOVER, Ada Pellegrini et al. Código brasileiro de defesa do consumidor: comentado pelos autores do anteprojeto. 7. ed. Rio de Janeiro: Forense, 2001.

FILOMENO, José Geraldo Brito. Manual de direitos do consumidor. 10. ed. São Paulo: Atlas, 2010.

GARCIA, Flávio Amaral. O Estado como consumidor. Fórum Administrativo, Belo Horizonte, v. 6 , n. 63 , p. 50 , maio 2006 . 
GASPARINI, Diogenes. Direito administrativo. 17. ed. São Paulo: Saraiva, 2012.

GONÇALVES, Renato Afonso. Direito do consumidor. 5. ed. São Paulo: Método, 2014.

JUSTEN FILHO, Marçal. Curso de direito administrativo. 11. ed. São Paulo: Revista dos Tribunais, 2015.

MARQUES, Cláudia Lima. Contratos no código de defesa do consumidor. 4. ed. São Paulo: Revista dos Tribunais, 2002.

MIRAGEM, Bruno. Curso de direito do consumidor. São Paulo: Editora Revista dos Tribunais, 2008.

NUNES, Rizzatto. Comentários ao código de defesa do consumidor. 8. ed. São Paulo: Saraiva, 2015.

PARANÁ. Tribunal de Justiça. RI 0007208-19.2014.8.16.0165 PR 0007208-19.2014.8.16.0165/0

(Acórdão). Relator: Fernando Swain Ganem, Data de Julgamento: 6jul.2015, 1ª Turma Recursal, Data de Publicação: 9 jul. 2015. Disponível em: https://tj-pr.jusbrasil.com.br/jurisprudencia/207116693/ processo-civel-e-do-trabalho-recursos-recurso-inominado-ri-720819201481601650-pr-00072081920148160165-0-acordao. Acesso em: 18 fev. 2019.

PASOLD, Cesar Luiz. Metodologia da pesquisa jurídica: teoria e prática. 11. ed. Florianópolis: Conceito Editorial, 2008

PASQUALOTO, Adalberto. Os serviços públicos no código de defesa do consumidor. Revista de Direito do Consumidor, São Paulo, n. 1, p. 130-148, jan./mar. 1992.

RIO GRANDE DO SUL. Tribunal de Justiça. AC: 70053980587 RS. Indenização por danos morais. Relator: Irineu Mariani, Data de Julgamento: 06/08/2014, Primeira Câmara Cível, Data de PublicaçãoDJ 18ago.2014.Disponívelem:https://tj-rs.jusbrasil.com.br/jurisprudencia/368914206/ apelacao-civel-ac-70070101845-rs. Acesso em: fev. 2019.

ROSA, Márcio Fernando Elias. Direito administrativo. 4. ed. São Paulo: Saraiva, 2012.

SILVA, André Pataro Myrrha de Paula e. A Administração Pública como consumidora e a aplicabilidade do Código de Defesa do Consumidor aos contratos administrativos. Revista Jus Navigandi, Teresina, v. 19, n. 3837, jan. 2014. Disponível em: http://jus.com.br/artigos/26309. Acesso em: 25 jul. 2015.

SZKLAROWSKY, Leon Frejda. O Código de Proteção e Defesa do Consumidor e os contratos administrativos. Revista Jus Navigandi, Teresina, v. 4, n. 30, abr. 1999. Disponível em: https:// jus.com.br/artigos/470. Acesso em: 23 jul. 2015. 
WURSTER, Tani Maria. Os serviços públicos e Código de Defesa do Consumidor. Revista de

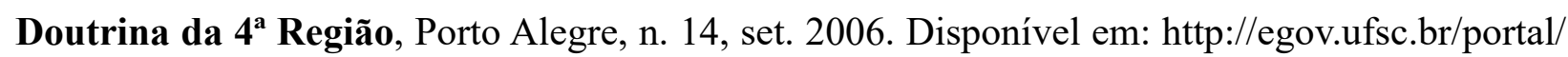
sites/default/files/anexos/19785-19786-1-PB.pdf. Acesso em: 23 jul. 2015.

Como citar: BELLETTI, Caroline; EFING, Antonio Carlos. Relações de consumo e serviços públicos: a figura do estado consumidor. Revista do Direito Público, Londrina, v. 14, n. 3, p. 168183, dez. 2019. DOI: 10.5433/24157-108104-1.2019v14n3p. 168. ISSN: 1980-511X

Recebido em: 26/06/2017

Aprovado em: 26/02/2019 